\title{
Commentary on "Infant Formulas Containing Hydrolysed Protein for Prevention of Allergic Disease and Food Allergy"
}

\author{
William McGuire $^{\mathrm{a}}$ Roger Soll $^{\mathrm{b}}$ \\ ${ }^{a}$ Centre for Reviews and Dissemination, University of York, York, UK; b Division of Neonatal-Perinatal Medicine, \\ University of Vermont, Burlington, VT, USA
}

\section{Commentary}

Although uncertainty exists about whether exposure to cow milk proteins in infancy affects the risk of developing allergic diseases in childhood, the European Academy of Allergy and Clinical Immunology recommends that young infants who need a supplement to maternal milk, and who are at high risk of developing allergy (usually because of a strong family history), should be fed with a hypoallergenic breast milk substitute (BMS) [1]. The most commonly used BMS in this context is a "hydrolysed" cow milk formula containing proteins digested chemically or enzymatically to oligopeptides. Several brands of hydrolysed formulas are available commercially and these vary by the degree of hydrolysis (extensive or partial) as well as by the main protein source (casein or whey-casein) and carbohydrate and fat type and content.

Is this recommendation evidence-based? In the updated Cochrane review of randomised controlled trials of the effect of feeding young infants at high risk of allergic disease with hydrolysed versus standard formulas, Osborn et al. suggest not [2]. The authors identified, appraised, and synthesised the data from 16 eligible trials. Most trials assessed whether prolonged supplemental or sole feeding with hydrolysed versus standard formula affected the risk of developing allergic diseases including asthma, atopic dermatitis, allergic rhinitis, and food allergy in infants with first-degree relative with allergic disease. Only trials with near-complete (at least $80 \%$ of the infants) outcome assessments were included to reduce the risk of attrition bias.

The meta-analysis of available outcome data did not show a difference in the incidence of allergic disease in infants (typical relative risk 0.88 , 95\% CI 0.76-1.01) (Fig. 1). There was evidence of heterogeneity in the metaanalysis, that is, the results between the trials varied by more than would be expected by chance. This may have been due to differences in the type of participants (level of risk of allergy), or interventions (type of hydrolysed formula), or how allergic diseases were defined and measured as outcomes (parent-reported, clinician- or laboratory-assessed). Furthermore, the analysis showed evidence of possible "publication bias"-asymmetry in the funnel plot indicating that smaller trials with larger effect sizes were over-represented (Fig. 2).

This finding is consistent with another systematic review that additionally included trials with lower rates of outcome assessments [3]. Both this review and the updated Cochrane review highlighted methodological quality issues within many of the included trials and in addition concerns about conflicts of interest related to study sponsorship and funding. Most of the included trials were supported by the manufacturers of the BMS being assessed, but there was no evidence that these conflicts of interest influenced the effect estimates for prespecified

\section{KARGER}

(c) 2019 S. Karger AG, Basel

E-Mail karger@karger.com

www.karger.com/neo
William McGuire

Centre for Reviews and Dissemination

University of York, University Road

York YO10 5DD (UK)

E-Mail william.mcguire@hyms.ac.uk 


\begin{tabular}{|c|c|c|c|c|c|c|c|c|c|c|c|}
\hline \multirow[t]{2}{*}{ Study or subgroup } & \multicolumn{2}{|c|}{ Treatment } & \multicolumn{2}{|l|}{ Control } & \multirow{2}{*}{$\begin{array}{l}\text { Weight, } \\
\%\end{array}$} & \multirow{2}{*}{$\begin{array}{l}\text { Risk ratio, } \\
\mathrm{M}-\mathrm{H} \text {, fixed }(95 \% \mathrm{Cl})\end{array}$} & \multirow{2}{*}{\multicolumn{3}{|c|}{$\begin{array}{l}\text { Risk ratio, } \\
\mathrm{M}-\mathrm{H} \text {, fixed }(95 \% \mathrm{Cl})\end{array}$}} & & \\
\hline & events & total & events & total & & & & & & & \\
\hline de Seta [5], 1994 & 8 & 23 & 18 & 39 & 4.6 & $0.75(0.39,1.45)$ & & & & - & \\
\hline Hill [6], 2000 & 102 & 191 & 71 & 147 & 27.9 & $1.11(0.89,1.37)$ & & & & $=-$ & \\
\hline Lam [7], 1992 & 16 & 44 & 28 & 48 & 9.3 & $0.62(0.39,0.99)$ & & & & & \\
\hline Marini [8], 1996 & 5 & 42 & 11 & 40 & 3.9 & $0.43(0.17,1.14)$ & & & & - & \\
\hline Oldaeus [9], 1997 & 35 & 95 & 15 & 46 & 7.0 & $1.13(0.69,1.85)$ & & & & & \\
\hline Vandenplas [10], 1992 & 7 & 32 & 17 & 35 & 5.7 & $0.45(0.22,0.94)$ & & & & & \\
\hline von Berg [11], 2003 & 176 & 1,465 & 66 & 483 & 34.6 & $0.88(0.68,1.14)$ & & & & & \\
\hline Willems [12], 1993 & 13 & 55 & 22 & 67 & 6.9 & $0.72(0.40,1.29)$ & & & & - & \\
\hline Total $(95 \% \mathrm{Cl})$ & & 1,947 & & 905 & 100.0 & $0.88(0.76,1.01)$ & & & & & \\
\hline Total events & 362 & & 248 & & & & & & & & \\
\hline \multicolumn{5}{|c|}{ Heterogeneity: $\chi^{2}=13.51, d f=7(p=0.06), I^{2}=48 \%$} & & & 0.2 & 0.5 & 1 & 2 & \\
\hline \multicolumn{5}{|c|}{ Test for overall effect: $Z=1.84(p=0.07)$} & \multicolumn{5}{|c|}{ Favours hydrolysed } & Favours s & \\
\hline
\end{tabular}

Fig. 1. Prolonged feeding with hydrolysed versus standard cow's milk formula. Effect on all allergic disease [5-12].

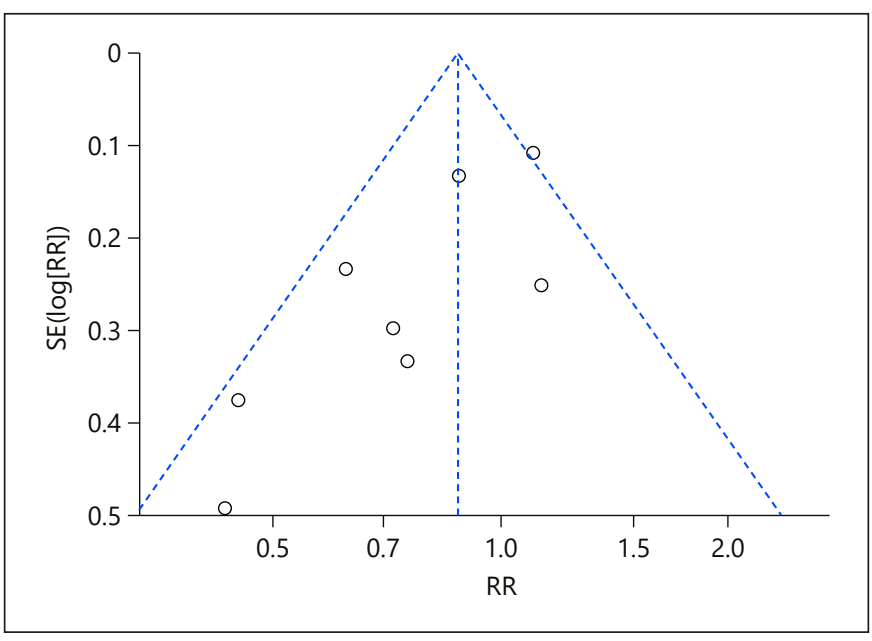

Fig. 2. Funnel plot of prolonged feeding with hydrolysed versus standard cow's milk formula. Effect on all allergic disease. RR, risk ratio. outcomes [3]. There remains some concern that BMS manufacturers may promote study findings of trials of specialist formulas selectively as part of a marketing strategy that subverts UNICEF Baby-Friendly Initiative regulations [4]. Policy and practice should now reflect this body of critically appraised evidence that indicates that hydrolysed formula does not prevent allergic disease in infants receiving a BMS.

\section{Acknowledgment}

Cochrane Neonatal Reviews are produced with support from the Vermont Oxford Network, a worldwide collaboration of health professionals dedicated to providing evidence-based care of the highest quality for newborn infants and their families. Editorial support for Cochrane Neonatal comes from a UK National Institute of Health Research (NIHR) Cochrane Programme Grant $(16 / 114 / 03)$.

\section{References}

1 Muraro A, Halken S, Arshad SH, Beyer K, Dubois AE, Du Toit G, et al.; EAACI Food Allergy and Anaphylaxis Guidelines Group. EAACI food allergy and anaphylaxis guidelines. Primary prevention of food allergy. Allergy. 2014 May;69(5):590-601.
2 Osborn DA, Sinn JK, Jones LJ. Infant formulas containing hydrolysed protein for prevention of allergic disease and food allergy. Cochrane Database Syst Rev. 2017 Mar;3: CD003664.
3 Boyle RJ, Ierodiakonou D, Khan T, Chivinge J, Robinson Z, Geoghegan N, et al. Hydrolysed formula and risk of allergic or autoimmune disease: systematic review and metaanalysis. BMJ. 2016 Mar;352:i974. 
4 Cleminson J, Oddie S, Renfrew MJ, McGuire W. Being baby friendly: evidence-based breastfeeding support. Arch Dis Child Fetal Neonatal Ed. 2015 Mar;100(2):F173-8.

5 de Seta L, Siani P, Cirillo G, Di Gruttola M, Cimaduomo L, Coletta S. The prevention of allergic diseases with a hypoallergenic formula: a follow-up at 24 months. The preliminary results. [Italian]. Pediatr Med Chir. 1994; 16(3):251-4.

6 Hill DJ, Sporik R, Thorburn J, Hosking CS. The association of atopic dermatitis in infancy with immunoglobulin $\mathrm{E}$ food sensitization. J Pediatr. 2000;137(4):475-9.
7 Lam BC, Yeung CY. The effect of breast milk, infant formula and hypoallergenic formula on incidence of atopic manifestation in high risk infants. Nestle Internal Report 1992.

8 Marini A, Agosti M, Motta G, Mosca F. Effects of a dietary and environmental prevention programme on the incidence of allergic symptoms in high atopic risk infants: three years' follow-up. Acta Paediatr Suppl. 1996; 414:1-21.

9 Oldaeus G, Anjou K, Bjorksten B, Moran JR, Kjellman NI. Extensively and partially hydrolysed infant formulas for allergy prophylaxis. Arch Dis Child. 1997;77(1):4-10.

10 Vandenplas Y, Hauser B, Van den Borre C, Sacre L, Dab I. Effect of a whey hydrolysate prophylaxis of atopic disease. Ann Allergy. 1992;68(5):419-24.
11 von Berg A, Koletzko S, Grubl A, Filipiak-Pittroff B, Wichmann HE, Bauer CP, et al; German Infant Nutritional Intervention Study Group. The effect of hydrolyzed cow's milk formula for allergy prevention in the first year of life: the German Infant Nutritional Intervention Study, a randomized double-blind trial. J Allergy Clin Immunol. 2003;111(3):53340.

12 Willems R, Duchateau J, Magrez P, Denis R, Casimir G. Influence of hypoallergenic milk formula on the incidence of early allergic manifestations in infants predisposed to atopic diseases. Ann Allergy. 1993;71(2):147-50.

(c) 2019 S. Karger AG, Basel

\section{Cochrane Abstract}

Background: Infant formulas containing hydrolysed proteins have been widely advocated for preventing allergic disease in infants, in place of standard cow's milk formula (CMF). However, it is unclear whether the clinical trial evidence supports this. Objectives: To compare effects on allergic disease when infants are fed a hydrolysed formula versus CMF or human breast milk. If hydrolysed formulas are effective, to determine what type of hydrolysed formula is most effective, including extensively or partially hydrolysed formula (EHF/PHF). To determine whether infants at low or high risk of allergic disease, and whether infants receiving early short-term (first few days after birth) or prolonged formula feeding benefit from hydrolysed formulas. Search Methods: We searched the Cochrane Central Register of Controlled Trials (CENTRAL 2017, Issue 11), MEDLINE (1948 to 3 November 2017), and Embase (1974 to 3 November 2017). We also searched clinical trials databases, conference proceedings, and the reference lists of retrieved articles and previous reviews for randomised controlled trials and quasi-randomised trials. Selection Criteria: We searched for randomised and quasi-randomised trials that compared use of a hydrolysed formula versus human milk or CMF. Outcomes with $\geq 80 \%$ follow-up of participants from eligible trials were eligible for inclusion. Data Collection and Analysis: Two review authors independently selected trials, assessed trial quality and extracted data from the included stud- ies. Fixed-effect analyses were performed. The treatment effects were expressed as risk ratio (RR) and risk difference (RD) with $95 \%$ confidence intervals and quality of evidence using the GRADE quality of evidence approach. The primary outcome was all allergic disease (including asthma, atopic dermatitis, allergic rhinitis and food allergy). Main Results: A total of 16 studies were included. Two studies assessed the effect of three to four days infant supplementation with an EHF while in hospital after birth versus pasteurised human milk feed. A single study enrolling 90 infants reported no difference in all allergic disease (RR 1.43, 95\% Cl 0.38-5.37) or any specific allergic disease up to childhood including cow's milk allergy (CMA) (RR 7.11, 95\% Cl 0.35143.84). A single study reported no difference in infant CMA (RR 0.87, 95\% Cl 0.52-1.46; participants = 3,559). Quality of evidence was assessed as very low for all outcomes. No eligible trials compared prolonged hydrolysed formula versus human milk feeding. Two studies assessed the effect of three to four days infant supplementation with an EHF versus a CMF. A single study enrolling 90 infants reported no difference in all allergic disease (RR 1.37, 95\% Cl 0.33-5.71; participants $=77$ ) or any specific allergic disease including CMA up to childhood. A single study reported a reduction in infant CMA of borderline significance (RR $0.62,95 \% \mathrm{Cl} 0.38$ 1.00; participants $=3,473$ ). Quality of evidence was assessed as very low for all outcomes. Twelve studies assessed the effect of prolonged infant feeding with a hydrolysed formula compared with a CMF. The data 
showed no difference in all allergic disease in infants (typical RR 0.88, 95\% Cl 0.76-1.01; participants $=2,852$; studies $=8$ ) and children (typical RR $0.85,95 \% \mathrm{Cl} 0.69$ 1.05; participants $=950$; studies $=2$ ), and no difference in any specific allergic disease including infant asthma (typical RR 0.57, 95\% Cl 0.31-1.04; participants = 318; studies $=4$ ), eczema (typical RR 0.93, 95\% Cl 0.79-1.09; participants $=2,896$; studies $=9$ ), rhinitis (typical RR $0.52,95 \% \mathrm{Cl} 0.14-1.85$; participants $=256$; studies $=3$ ), food allergy (typical RR 1.42, 95\% Cl 0.87-2.33; participants $=479$; studies $=2)$, and CMA (RR 2.31, 95\% Cl 0.2421.97; participants $=338$; studies $=1$ ). Quality of evi- dence was assessed as very low for all outcomes. $R \boldsymbol{e}$ viewers' Conclusions: We found no evidence to support short-term or prolonged feeding with a hydrolysed formula compared with exclusive breast feeding for prevention of allergic disease. Very low-quality evidence indicates that short-term use of an EHF compared with a CMF may prevent infant CMA. Further trials are recommended before implementation of this practice. We found no evidence to support prolonged feeding with a hydrolysed formula compared with a CMF for prevention of allergic disease in infants unable to be exclusively breast fed [see Ref. 2]. 